\title{
OS NOVOS DESAFIOS DA ADVOCACIA TRIBUTÁRIA E A ARBITRAGEM FISCAL EM DESTAQUE
}

\author{
THE NEW CHALLENGES OF TAX \\ ADVOCACY AND FISCAL ARBITRATION
}

BRUNO BASTOS DE OLIVEIRA ${ }^{1}$

MARIA DAS GRaÇAS MACENA Dias DE OLIVEIRA ${ }^{2}$

\section{RESUMO}

O presente artigo faz um estudo sobre os novos desafios enfrentados pela advocacia tributária no contexto das mudanças demandas pela realidade do século XXI. Vivencia-se o esgotamento da capacidade do poder Judiciário em atender aos anseios da sociedade, em especial no que tange aos conflitos de natureza fiscal. Assim, a arbitragem fiscal surge como mecanismo adequado, porém questiona-se se a advocacia já está preparada para essa realidade, bem como o papel do advogado nesse contexto. Outro questionamento a ser enfrentado reside na possibilidade de implementação da arbitragem fiscal no ordenamento jurídico brasileiro. A partir de método de pesquisa dedutivo, com técnica exploratória, bibliográfica e qualitativa, conclui-se que a falta de efetividade dos meios existentes para a solução de conflitos, em especial os de natureza tributária, revela grande insegurança jurídica, devendo a advocacia estar preparada para essa nova realidade que se apresenta, na atuação de lides arbitrais.

Palavras-chave: Advocacia tributária. arbitragem fiscal. eficiência.

\section{ABSTRACT}

This article makes a study about the new challenges faced by tax law in the context of the changing demands for the reality of the 21 st century. There is an exhaustion of the capacity of the Judiciary to meet the needs of society, especially with regard to conflicts of a fiscal nature. Thus, tax arbitration appears as an adequate mechanism, but it is questioned whether the legal profession is already prepared for this reality, as well as the role of the lawyer in this context. Another question to be faced is the possibility of implementing tax arbitration in the Brazilian legal system. Based on a deductive research method, with exploratory, bibliographic and qualitative techniques, it is concluded that the lack of effectiveness of the existing means for resolving

1 Professor Permanente do PPGD UNIMAR. Doutor em Direitos Humanos e Desenvolvimento e Mestre em Direito Econômico, ambos pela UFPB. Especialista em Direito Tributário pela UNISUL. ORCID: http://orcid.org/0000-0002-4563-6366. E-mail: bbastos.adv@gmail.com.

2 Mestranda em Direito no PPGD UNIMAR. E-mail: mariamacenaadv@gmail.com. 
conflicts, especially those of a tax nature, reveals great legal uncertainty, and the law must be prepared for this new reality that presents itself, in the performance of arbitration cases.

Keywords: Tax advocacy. tax arbitration. efficiency.

\section{INTRODUÇÃO}

O mundo globalizado, a sociedade informacional e o avanço da tecnologia se apresentam como fatores impactantes para a modificação estrutural das mais antigas profissões que se tem conhecimento, estando a advocacia inserida nesse contexto de ruptura de paradigmas, próprio do século XXI.

Vivencia-se no Brasil, com especial destaque, uma sociedade extremamente conflituosa, ou seja, as mais diversas relações jurídicas que se estabelecem no meio social tendem a se transformar em litígios que acabam refletindo na maximização significativa do papel do Poder Judiciário, que não consegue desempenhar seu mister com eficiência e celeridade, por inúmeras razões.

Fato é que o profissional da advocacia, inserido nesse contexto, passa por determinante momento de reinvenção, enfrentando novos desafios, sendo o principal deles a ruptura com padrão de atuação fundamentalmente litigiosa, pautada na condução única e exclusiva do litígio já judicializado.

Dentre as mais diversas relações jurídicas materializadas no âmbito social, destaca-se no presente estudo a relação jurídica tributária entre Estado e contribuinte, por natureza, conflituosa e desigual.

A partir de uma pesquisa exploratória, bibliográfica e qualitativa, pretende-se delinear a falta de efetividade dos meios existentes para a solução de conflitos, em especial os de natureza tributária, em um quadro de grande insegurança jurídica e de afastamento gradativo e decisivo do ideal de justiça incorporado pelo texto constitucional vigente.

Defendendo a necessidade de evoluir no sentido de regulamentação legislativa da arbitragem em matéria tributária, com a desburocratização do sistema como um todo, tornando-o mais eficiente e seguro juridicamente, e a contribuição para maior efetividade no recebimento do gigantesco passivo existente no que tange à arrecadação de tributos, especialmente por parte da União Federal, é preciso posicionar a advocacia desse contexto de desjudicialização dos conflitos, com os desafios próprios de um início de século que ficará marcado como responsável pela profunda mudança na perspectiva de atuação de profissionais da advocacia, seja ela privada ou pública.

\section{ADVOCACIA TRIBUTÁRIA: NOVOS DESAFIOS DO SÉC. XXI}

A advocacia como um todo e mais especificamente a tributária vem passando por significativas mudanças nos últimos anos, isso em decorrência de inúmeros fatores, dentre os 
quais destacam-se o esgotamento da capacidade de solução eficaz dos conflitos fiscais por parte do Poder Judiciário. Assim, imprescindível adentrar sobre os aspectos que envolvem essa mudança paradigmática.

\subsection{ESGOTAMENTO DA CAPACIDADE DE SOLUÇÃO EFICAZ DOS CONFLITOS FISCAIS POR PARTE DO PODER JUDICIÁRIO}

O completo esgotamento da capacidade de solução eficaz dos conflitos por parte do Poder Judiciário brasileiro é fato que impacta definitivamente na advocacia tributária, fazendo com que os profissionais que nela estejam inseridos necessitem pensar adiante, criando novas expertises para adequação a modelos de advocacia que sejam mais eficientes e tragam retorno mais desejável, tanto ao cliente quanto ao próprio profissional.

Identificar o Poder Judiciário como sendo o único capaz de, por meio do processo e das consequentes decisões terminativas, oferecer respostas confiáveis e legítimas aos conflitos oriundos das relações jurídicas impregnadas no cotidiano das pessoas físicas e jurídicas, mostra-se claro equívoco. Da mesma forma, a advocacia que se pauta nesse modelo está fadada a enfrentar sérias dificuldades. A crise institucional vivenciada pelo Poder Judiciário nos últimos tempos não pode ser desconsiderada. Nesse sentido, essa crise mencionada, de efetividade principalmente, representa certa fraqueza do sistema do Estado constitucional, porém não é possível considerar a existência de modelos perfeito, sendo a capacidade do Judiciário de fazer justiça verdadeiro teste de estabilidade (VECCHIO, 2020, p. 22).

A consolidação da ideia de que "quanto mais longo o procedimento, com maior número de recursos e oportunidades para as partes se manifestarem, mais justa seria a decisão final" (1999, p. 79) foi responsável pelo gradativo aumento na litigiosidade estatal, o qual continua em efetiva progressão.

Para enfrentar o cenário de expansão da litigiosidade e consequente esgotamento do Poder Judiciário, é possível citar alguns avanços expressivos, como a edição da Lei $\mathrm{n}^{\circ}$ 9.099/95 (Lei dos Juizados Especiais), que prevê a conciliação; da Lei nº 9.307/96, que versa sobre a arbitragem; da Resolução n $125 / 10$ do CNJ, regulamentando a Política Judiciária Nacional de tratamento adequado dos conflitos de interesses no âmbito do Poder Judiciário; da Lei no 13.140/15, a qual dispõe sobre a auto composição de conflitos, inclusive, no âmbito da própria Administração Pública; e do próprio Código de Processo Civil de 2015 (Lei n 13.105/15 - CPC/15), o qual menciona a arbitragem, conciliação e mediação já no capítulo inicial, que trata sobre as normas fundamentais do processo civil.

Ainda assim, a taxa de congestionamento do Poder Judiciário ainda é alta a ponto de comprometer a qualidade da prestação jurisdicional - 73\% (setenta e três por cento), de acordo com o último Relatório Justiça em Números 2017: ano-base 2016, elaborado pelo CNJ (CNJ, 2017).

As questões tomam proporções ainda mais graves quando se tem por base os conflitos estabelecidos entre fisco e contribuinte. Sobre os conflitos de natureza fiscal, os mesmos normalmente residem ou na diferente qualificação jurídica dada aos fatos ou mesmo nas diferentes interpretações dadas a determinado dispositivo legal, vez que o direito tributário é pautado pelo princípio da legalidade. 
A "cultura do litígio" está inserida dentro da perspectiva de gradativa perda da capacidade de solução consensual dos conflitos surgidos na sociedade. Se no âmbito das relações privadas, nas quais prevalece a autonomia da vontade e a regra da disponibilidade patrimonial, esse panorama é evidente, ainda mais grave é a situação quando se tem a Administração Pública inserida no conflito, suportando-se aí análises mais complexas como aquela acerca da supremacia ou da indisponibilidade do interesse público.

A superação dessa "cultura do litígio" passa, necessariamente, pela modificação da mentalidade jurídica de todos aqueles que fazem parte do sistema jurídico, inclusive, e principalmente, os advogados, inseridos em uma posição primordial no que tange ao estímulo à consensualidade

É nesse espaço de crescente consensualidade que a arbitragem surge como meio adequado para solução das disputas que envolvam a Administração Pública, ressaltando a ideia do sistema multiportas. A própria reforma na legislação processual civil ocorrida com a promulgação do vigente Código de Processo Civil marca a definitiva evolução no entendimento nacional acerca dos meios adequados para solução dos conflitos.

$\mathrm{O}$ cidadão teria à disposição várias alternativas para solucionar um conflito. $\mathrm{O}$ objetivo do sistema multiportas é buscar formas de solução de conflitos que substituam o tradicional sistema judicial de solução de litígios ou que essas novas formas possam coexistir com a tutela jurisdicional estatal (BRANDÃO, 2014, p. 24).

É possível notar que a bem da verdade, a opção por vias alternativas ao processo judicial clássico marca verdadeira ruptura a padrão cultural histórico, sendo, pois, fundamental que haja a massificação dessas ideias com vistas a se atingir grau elevado de busca por meios que possam solucionar os litígios de maneira mais adequada e efetiva.

A elevada taxa de congestionamento do Poder Judiciário, aliada à sua deficitária estrutura, faz com que seja evidenciada a grave crise que assola as entranhas dos órgãos judicantes. 0 mais preocupante é que a Administração Pública, especialmente no âmbito federal, é a maior responsável pelo elevado número de processos em trâmite.

A mudança desse paradigma de litigiosidade não significa desconsiderar o importante papel exercido pelo Poder Judiciário, que deve pautar suas decisões sempre "no resultado prático e eficaz na resolução do conflito social, e não somente na mera afirmação de vencedor e vencido, pois, isto pode ocasionar o fomento da litigiosidade" (MACEI; VOSGERAU; ANDRETTA, 2020, p. 14), o que por si só vai de encontro aos que dispõe a própria Constituição Federal, ao estabelecer como objetivo fundamental da República a construção de uma sociedade livre, justa de solidária.

Ademais, percebe-se ainda que a concentração de poder nas mãos do Judiciário não é, em sua essência, positiva para a sociedade. Sobre o tema, Martonio Mont'Alverne Barreto Lima e Evaldo Ferreira Acioly Filho (2019, p. 96) afirmam:

Essa concentração de poder na mão do Judiciário revela-se perigosa, pois a partir da análise da história política brasileira percebe-se uma tentativa de concentrar e fortificar o controlador e intérprete desde a época do Império. Falo do Poder Moderador que assim como o Judiciário, se colocava como um terceiro neutro, quando, na verdade, escondia seu caráter conservador. Ora, quando se dilata os poderes dos juízes que, normalmente não são eleitos reveste-se também a jurisdição constitucional de um aspecto conservador, 
pois o judiciário passa a deter o monopólio da moral e da ordem pública de um Estado, determinando o que uma constituição é ou não é. Esse monopólio diverge, também, da soberania popular, pois um poder estatal - Judiciário - se auto limita, excluindo a participação popular, rompendo com aspecto democrático da constituição

Assim, é preciso que a advocacia esteja antenada a esse cenário que se apresenta. 0 advogado do século XXI não é, e nem poderia ser, o advogado com a mentalidade do litígio.

\subsection{ADVOCACIA PREVENTIVA, EXTRAJUDICIAL OU NEGOCIAL}

A histórica e relevantíssima atividade da advocacia, no Brasil regulamentada pela Lei $\mathrm{n}$. 8.906/94 (Estatuto da OAB), bem como pelo Regulamento Geral, Código de Ética e Disciplina e Provimentos do Conselho Federal, precisa ser repensada. A bem da verdade, nos últimos anos esse processo de reflexão e debate sobre o verdadeiro papel do advogado vem sem aprofundado e já é possível identificar um estágio de profundas mudanças.

Em que pese se tratar de atividade de índole predominantemente privada, não há como refutar o importante papel que o advogado assume perante a sociedade, já que é através dele que o ele em relação ao Poder Judiciário é concretizado. Ademais, a própria Constituição Federal, em seu art. 133, trata de elevar a advocacia a um patamar não pertencente a nenhuma outra profissão liberal, uma vez considerar o advogado como sendo indispensável à administração da Justiça.

Ao lado das prerrogativas, os advogados possuem também responsabilidades bem postas, tais como a defesa incansável da Constituição, do Estado Democrático de Direito, dos direitos humanos e da justiça social. Nestes termos preconiza o art. 44, I do Estatuto da Ordem dos Advogados do Brasil.

A legislação processual vigente no país atribui ao advogado, como regra, a exclusividade no que tange à capacidade postulatória, ou seja, somente o advogado, regularmente inscrito nos quadros da Ordem dos Advogados do Brasil, após aprovação em exame de aptidão técnica, poderá postular em juízo. Assim, o domínio da capacidade de postular é inerente à própria atividade, sendo que, via de regra, isso se dá no âmbito da existência de um conflito entre duas ou mais partes, conflito esse que será levado ao Judiciário para que haja a prestação jurisdicional adequada.

É quase naturalmente verificável a proximidade que a atividade advocatícia possui com a constante gestão de conflitos, em que pese essa gestão seja historicamente resumida à defesa em juízo com vistas a alcançam uma decisão judicial que favoreça o constituinte.

A despeito dessa contextualização, forçoso entender que em pleno século XXI não há mais o mesmo espaço ao profissional advogado que simplesmente postula em juízo, ou seja, aquele que litiga. Historicamente o "bom advogado" era aquele considerado "bom de briga", ideia que vem sendo aos poucos esvaziada, na medida que as pessoas buscam agora profissional que possa solucionar o problema concreto sem que haja a judicialização da questão, de preferência. 0 advogado, na sociedade atual, está preocupado em encontrar soluções racionais aos conflitos antes mesmo de que os mesmos cheguem ao Poder Judiciário, sendo exatamente neste ponto que ganha relevo a advocacia negocial, extrajudicial ou preventiva. 
Sobre esse papel preventivo da advocacia, Paulo Lôbo (2009, p. 20) afirma que "um dos grandes males da formação jurídica, no Brasil, é a destinação predominantes dos cursos jurídicos ao litígio". Tal conclusão parece bastante lógica, haja visto que o Poder Judiciário em colapso se mostra completamente esgota e sem capacidade de entregar à sociedade respostas ágeis e eficiente. Nessa perspectiva, complementa o autor afirmando que:

[...] a área mais dinâmica das profissões jurídicas, na atualidade, é a atuação extrajudicial, em várias dimensões. Podemos encará-las de dois modos: como atividades preventivas e como atividades extrajudiciais de solução de conflitos. No primeiro caso, busca-se evita-los. No segundo, buscam-se meios distintos do processo judicial para solucionar conflitos já instalados ou com potencial litigiosidade; este é o campo das mediações, das negociações individuais ou coletivas, da arbitragem [...]

Não há como vislumbrar realidade diferente da retratada acima. A grande questão parece ser localizar o exercício da advocacia nesse cenário de mudança de paradigma. Nesse aspecto, continua Paulo Lôbo (2009, p. 20) afirmando:

[...] o advogado é profissional especializado, cuja assessoria ou consultoria é imprescindível, independentemente de mandamento legal, pela demanda crescente a seus serviços vinda de pessoas, empresas, entidades, grupos sociais e movimentos populares. Esse vasto campo profissional requer habilidades que os cursos jurídicos devem considerar, porque a tendência é a crescente desjudicialização de suas atividades.

Esse contexto faz com que os profissionais advogados necessitem complementar suas formações com conhecimentos específicos que os capacitem para atuar nessas novas frentes, primeiro evitando que os conflitos ocorram e, sendo impossível a prevenção, encontrando caminhos para solução desses litígios fora do clássico âmbito judicial.

Nesse ponto, questiona-se, por exemplo, se a advocacia está preparada e qualificada adequadamente para atuar com negociação, mediação e arbitragem. A resposta mais segura tende a ser negativa.

Não há como se falar em busca de meios adequados para solução dos conflitos, especialmente os de natureza fiscal, se todos os que atuam na gestão desses conflitos não estiverem capacitados para as novas tendências processuais. 0 que é defendido no presente trabalho é a implementação da arbitragem em matéria fiscal, conforme será adiante aprofundado, porém tal realidade implica uma nova advocacia, que efetivamente saiba atuar fora do campo judicial de solução de conflitos.

\subsection{A BUSCA DE MEIOS ADEQUADOS PARA SOLUÇẤO DOS CONFLITOS TRIBUTÁRIOS}

Em última e simplória análise, o advogado que estimula o litígio e nessa única vertente labora, está fadado a criar um ambiente hostil e de repulsa perante os próprios clientes, vez que ninguém consegue efetivamente ganhar com processos tramitando no Poder Judiciário por anos e anos, sem uma solução efetiva e adequada.

No contexto de esgotamento do Judiciário, observa-se um movimento de reformas legislativas significativas, implementando-se meios consensuais de resolução de conflitos, 
com a capacidade de oferecer à sociedade novas formas, por vezes muito mais eficazes, de se chegar ao mais próximo possível do que se entende sobre pacificação dos conflitos (SILVA; SANTOS; SILVA, 2020).

Mediante o exame do quadro de ineficiência estatal retratado com ênfase nas soluções ofertadas pelo Poder Judiciário ao tentar solucionar os conflitos inseridos na esfera tributária, verifica-se que a utilização de outros mecanismos adequados para responder a esse tipo de demanda não é apenas necessário, como deve ser almejado pelos operadores do direito, desde que devidamente fundamentada a sua possibilidade de harmoniosa convivência com o ordenamento jurídico brasileiro estabelecido.

Paulo Eduardo Alves da Silva (2012, p. 45) explica que:

Cada sociedade desenha o quadro de métodos de resolução de conflitos conforme as suas expectativas acerca do que seja ou não formal, o que seja ou não seguro, o que seja ou não violento e, principalmente, o que seja ou não justo. E, no último século, as sociedades contemporâneas tem demonstrado atravessar um estado de crise com seus conceitos de forma, segurança, violência e justiça. Naturalmente, isso compromete a hegemonia da jurisdição e do processo judicial e abre flancos para o ressurgimento de métodos 'alternativos' de solução de controvérsias.

Mais do que uma alternativa à entrega jurisdicional clássica efetivada pelo Poder Judiciário, a busca por mecanismos que se mostrem adequados às especificidades das controvérsias surgidas na contemporaneidade se mostra como uma necessidade, assim como a necessária adaptação de todos que margeiam essa realidade.

Assenta-se que "a busca por um sistema paralelo para colaborar com o modelo oficial é não apenas oportuna, como essencial" (PINHO; PAUMGARTTEN, 2016, p. 27), sobretudo porque a expansão do número de métodos colocados à disposição das partes implica em maiores probabilidades de alcançar um resultado adequado ao tipo de conflito que precisa ser solucionado, trazendo resultados interessantes, inclusive no campo econômico, tanto às partes quanto aos advogados envolvidos.

Entre os principais mecanismos adequados que se apresentam no âmbito jurídico estão a mediação, a conciliação e a arbitragem, sendo que as duas primeiras se identificam por serem métodos consensuais na forma autocompositiva, enquanto a arbitragem é caracterizada pela heterocomposição, de base consensual.

Ainda que exista um longo caminho a ser percorrido, dados da Câmara de Comércio Internacional (CCI) apontam que, em 2016, o país foi considerado o 5 o (quinto) no mundo que mais utiliza a arbitragem para a solução de conflitos, atrás de países como Estados Unidos da América e França. ${ }^{3}$

Outro dado importante é o fornecido pela Centro de Arbitragem e Mediação da Câmara de Comércio Brasil Canadá (CAM-CCBC), pioneira no Brasil em matéria de arbitragem, ao citar que estatísticas apontam que há gradativo aumento do número de arbitragens realizadas, especialmente a partir do ano de 2013.

3 Informação disponível em: https://www.jota.info/justica/brasil-e-o-5o-pais-que-mais-utiliza-arbitragem-no-mundo-19092017. 
Tudo que aqui é defendido se coaduna com o princípio constitucional da eficiência na Administração Pública, que pressupõe, ao mesmo tempo, a modernização estatal, inclusive no que tange à regulamentação e efetivação de meios adequados para solução de litígios, especialmente os de natureza tributária (OLIVEIRA; OLIVEIRA; CARMO, 2019).

O que aqui se defende situa-se no campo da necessidade de adaptação e adequação da advocacia a esse novo cenário que se apresenta, sob pena desses métodos adequados de solução de conflitos, especialmente na área fiscal, ficarem apenas como parâmetros formais, sem nenhum grau de efetividade.

\section{ARBITRAGEM TRIBUTÁRIA: UMA NOVA PERSPECTIVA}

A arbitragem tributária se apresenta como possibilidade interessante dentro da perspectiva de solução adequada dos conflitos de natureza fiscal, motivo pelo qual se faz necessário aprofundar os estudos sobre alguns aspectos fundamentais que permeiam o instituto.

\subsection{ALGUMAS PREMISSAS ACERCA DA ARBITRAGEM}

A arbitragem pode perfeitamente ser validada como tecnologia jurídica capaz de solucionar alguns problemas enfrentados, primordialmente em questões de natureza tributária, colaborando decisivamente para a solução de vários problemas de efetividade vivenciados na atualidade, porém, para que isso se efetive é preciso que haja a implantação de uma nova cultura jurídica acerca do litígio, envolvendo todos os atores que atuam na solução dos conflitos.

É evidente que a clássica visão litigiosa do processo é decorrente do fato de que a adequada e justa resolução do objeto litigioso é função preponderantemente exercida pelos órgãos do Poder Judiciário, com o nítido objetivo de pacificação social, ou seja, o este poder estatal tem resguardado a si a exclusividade do exercício da tutela jurisdicional.

Em que pese a existência dessa clássica visão de exclusividade da tutela jurisdicional, percebe-se atualmente a existência de um sentimento de renovação no direito processual brasileiro. Para Jonathan Vita (2006, p. 205), vive-se essa onda renovatória, em que a busca por outros meios adequados para solução dos conflitos deságua na valorização cada vez mais efetiva de mecanismos como a conciliação, a mediação e a arbitragem. Parece óbvio que a advocacia não pode e não deve estar alheia a essa real mudança de paradigma.

Como mencionado, dentro dessa perspectiva de renovação surge a arbitragem, considerada meio heterocompositivo de solução de conflitos, vez que não há entre as partes a uniformização de um entendimento consensual, sujeitando-se ambas à solução apresentada por um terceiro (árbitro ou tribunal arbitral) que está fora do contexto do Poder Judiciário, sendo lícito se falar em evidente renúncia à jurisdição estatal quando da aceitação de uma cláusula compromissória. 
O processo arbitral pressupõe a existência de direitos disponíveis, sendo este um ponto de controvérsia quando se fala de arbitragem em matéria tributária. Fato é que, havendo a disponibilidade em relação à jurisdição estatal, o que se dá através do compromisso arbitral, o Poder Judiciário não poderá intervir, a não ser em momento posterior à sentença arbitral, em caso de algum vício que anule por completo o próprio procedimento, e não a essência da decisão constante na sentença arbitral.

O tratamento conceitual dado à arbitragem por parte da doutrina, em geral pode ser sistematizado pelas palavras de Francisco José Cahali (2015, p. 117), para quem a arbitragem se colocada, ao lado da jurisdição estatal, como um mecanismo heterocompositivo de solução de conflitos, onde as partes envolvidas, possuidoras de capacidade plena e de comum acordo, estabelecem que um terceiro, ou mesmo um colegiado, terá poderes para solucionar a controvérsia. Importante destacar, nesse contexto, que a solução do conflito se dá através de decisão do arbitro, que terá a mesma eficácia de uma sentença judicial.

Há quem advogue a tese de que na arbitragem existe uma espécie de "privatização da justiça", o que de fato não é aceitável. Sob tal aspecto, Beraldo (2014, p. 25), entende que a arbitragem não pode ser vista como a "ascensão judiciosa do neoliberalismo triunfante", refutando-se assim a ideia de "privatização da justiça", simplesmente pelo fato de que há décadas vem sendo objeto de larga expansão em outros países.

É possível citar inúmeros benefícios da utilização da arbitragem, em especial a produção de decisões efetivamente técnicas. Tal aspecto deve ser extremamente valorizado quando se fala em arbitragem tributária, já que os litígios fiscais, muitas vezes, se resumem à discordância sobre algum aspecto eminentemente técnico entre fisco e contribuinte, tal como a classificação de produtos para fins de imposição da exação tributária.

Quando se depara com demandas complexas, que envolvem questões técnicas sobre as quais o Poder Judiciário não possui domínio pleno, é possível entender o quanto o processo jurisdicional clássico se revela esgotado, não conseguindo apresentar soluções com o mínimo da efetividade almejada pelo jurisdicionado

Sobre a natureza jurídica da arbitragem, Carmona (1993, p. 25) afirma que: "parece ser universal a tendência de ampliar o conceito de jurisdição, na medida em que aumenta o grau de participação e o interesse popular na administração da justiça, revelando um dos escopos fundamentais da jurisdição, o político". Evidente a necessidade dessa ampliação, privilegiando-se, assim, o elemento teleológico da atividade jurisdicional.

No que pese a autonomia da vontade como norma fundamental, há nos sistemas jurídicos estrangeiros a previsão de situações nas quais a submissão ao juízo arbitral é obrigatória, tal como ocorre na Constituição da República Portuguesa, que faz expressa menção aos "tribunais arbitrais" em seu art. 2094. Outro exemplo citado pelo doutrinador é a Costa

4 "Art. 209. ${ }^{\circ}$ Categorias de tribunais 1. Além do Tribunal Constitucional, existem as seguintes categorias de tribunais: a) 0 Supremo Tribunal de Justiça e os tribunais judiciais de primeira e de segunda instância; b) O Supremo Tribunal Administrativo e os demais tribunais administrativos e fiscais; c) 0 Tribunal de Contas. 2. Podem existir tribunais marítimos, tribunais arbitrais e julgados de paz. 3. A lei determina os casos e as formas em que os tribunais previstos nos números anteriores se podem constituir, separada ou conjuntamente, em tribunais de conflitos. 4. Sem prejuízo do disposto quanto aos tribunais militares, é proibida a existência de tribunais com competência exclusiva para o julgamento de certas categorias de crimes." Arbitragem onio. Latin, 2016, p. 307.al, Financeiro e Economico r a forma pela qual seus conflitos ser Supremo Tribunal Federal 
Rica, onde há obrigatoriedade de participação do juízo arbitral nas questões relacionadas à previdência social.

A ideia de autonomia da vontade como "mola propulsora" da arbitragem em todos os seus aspectos se consolida, se revelando desde a faculdade que as partes possuem em determinado negócio envolvendo direitos patrimoniais disponíveis de adotarem esta via opcional de solução de conflitos, até o desenvolvimento do processo arbitral quando, por exemplo, da forma como serão indicados e escolhidos os árbitros. Fato é que se mostra perfeitamente possível extrair da Lei 9.307/96 vários artigos que indicam a relação estreita da arbitragem com a autonomia da vontade, o que será adiante analisado de forma mais detida.

\subsection{NECESSÁRIA SUPERAÇÁO DE PARADIGMAS}

Assentadas algumas premissas, é preciso avançar nas discussões sobre a possibilidade de utilização da arbitragem para solução de conflitos que envolvam os interesses da Administração Pública, a partir da própria interpretação da Lei $n^{\circ} 13.129 / 15$, que alterou a LArb, para que seja possível defender a utilização desse meio adequado para solução de conflitos de natureza fiscal.

No Brasil há grande resistência à arbitragem tributária, mesmo sendo possível verificar que o instituto é amplamente difundido em vários países, tal como ocorre em Portugal, por exemplo. Hugo de Brito Machado (2008, p. 130) defende a impossibilidade da solução arbitral para lides fiscais a partir da defesa de que o direito de arrecadação de tributos, inerente à Fazenda Pública, seria indisponível. Nota-se claramente que o ponto de discussão gira em torno da (in) disponibilidade do direito para se legitimar a utilização do processo arbitral. Apesar disso, o instituto não é novo.

A Nova Consolidação das Leis das Alfândegas e Mesas de Rendas, aprovada em 13 de abril de 1894, já previa a instituição da arbitragem em matéria tributária, principalmente para o julgamento de temas pertinentes às áreas aduaneiras (SEIXAS FILHO, 2008, p. 221).

No contexto da relação jurídica tributária a principal necessidade estatal é a satisfação do crédito tributário, vez que só assim o Estado terá capacidade financeira para a realização daquilo que se propõe, nos termos dos objetivos fundamentais expostos na CF/88 em seu art. 3o. Esse dispositivo é a base angular de toda atividade tributária do Estado e deve ser encarado com tal para a tributação assuma a sua real função social.

Para fins de defesa da arbitrabilidade tributária, dois são os elementos importantes que podem ser extraídos dessas premissas básicas relacionadas à relação jurídica tributária. 0 primeiro é o caráter pecuniário do tributo, a partir do próprio conceito legal de tributo trazido no art. 3o do (CTN) ${ }^{6}$ (BRASIL, 1966), para quem tributo é prestação pecuniária compulsória, logo de índole eminentemente patrimonial. O segundo é o fato de a cobrança se dar mediante atividade administrativa plenamente vinculada, o que não inviabiliza a possibilidade do Poder

5 "Art. $3^{\circ}$ Constituem objetivos fundamentais da República Federativa do Brasil: I - construir uma sociedade livre, justa e solidária; II - garantir o desenvolvimento nacional; III - erradicar a pobreza e a marginalização e reduzir as desigualdades sociais e regionais; IV - promover o bem de todos, sem preconceitos de origem, raça, sexo, cor, idade e quaisquer outras formas de discriminação."

6 "Art. $3^{\circ}$ Tributo é toda prestação pecuniária compulsória, em moeda ou cujo valor nela se possa exprimir, que não constitua sanção de ato ilícito, instituída em lei e cobrada mediante atividade administrativa plenamente vinculada." 
Público submeter à arbitragem as controvérsias surgidas, buscando-se solução diversa da jurisdição estatal clássica.

Segundo Casella e Escobar (2016, p. 746), a doutrina internacional divide as categorias da arbitragem fiscal como: Controvérsias tributárias decorrentes de relações negociais; Acordos para evitar a dupla tributação; Disputas fiscais entre um investidor estrangeiro e o país investido. Os autores entendem que tal divisão leva em conta apenas o mérito e a abrangência das controvérsias. Assim, propõem uma classificação que se entende ser extremamente relevante para o que aqui se propõe, levando-se em consideração o tempo do litígio, o mérito e a sua abrangência, qual seja: a) Quanto ao tempo: se dividiria em preliminar e preventivamente à constituição do crédito tributário; ou subsequente à constituição do crédito tributário; b) Quanto ao mérito: se divide em direta - analisando diretamente as questões tributárias; ou indireta - quando dos laudos arbitrais surge um novo fato jurídico tributário (fato gerador); c) Quanto à abrangência: se divide em interna - quando se dá dentro da estrutura federativa interna ou entre Administração e contribuintes nacionais; internacional estatal - envolvendo acordos para evitar dupla tributação; ou internacional mista - quando envolver um Estado e um entre privado estrangeiro.

A proposta dos autores resume as formas que a arbitragem tributária pode se apresentar, tanto no âmbito internacional como no âmbito interno. Interessante observar nessa classificação a possibilidade da arbitragem ter espaço antes da constituição definitiva do crédito tributário, por meio do lançamento, o que, no entender de Priscila Mendonça (2014, p. 115) seria medida promotora de um crescente diálogo entre Fisco e contribuinte.

Trata-se de posicionamento relevante na medida que a alta litigiosidade impregnada na relação jurídica tributária faz com que Fisco e contribuinte cada vez dialoguem menos, ou seja, a relação é permeada por um lado pelo autoritarismo e por outro pela incessante fuga da tributação.

A questão parece ser a quebra de paradigmas para que esse meio heterocompositivo de solução de conflitos possa ser implementado no Brasil, o que se defende na presente tese como sendo algo impactante para colaborar com a superação da grave crise econômica que assola o país nos últimos anos, de base preponderantemente fiscal.

De maneira geral, as discussões sobre a possibilidade ou não da utilização da arbitragem nas controvérsias de natureza fiscal repousam na questão da interpretação acerca da disponibilidade ou não do crédito tributário, o que será detidamente analisado adiante. Vale ressaltar que este crédito é aquele decorrente da relação jurídica tributária e representa o direito subjetivo do Estado em arrecadar o produto da exação tributária.

Mesmo diante dos argumentos desfavoráveis, acredita-se que a utilização desse meio para solução dos conflitos fiscais se mostra como verdadeira necessidade. 0 professor português Diogo Leite de Campos (2005, p. 50) assim defende:

O interrelacionamento justo entre o cidadão e o Estado a nível dos impostos, com a assunção "livre" e espontânea por aquele das suas obrigações fiscais - como princípio e ponto de partida - passa pela assunção livre da regulação de conflitos entre credor e devedor. Passa, por outras palavras, pela faculdade de recorrer à arbitragem. Com todas as vantagens que esta acarreta no que se refere à certeza e segurança do Direito. Nomeadamente: escolha dos juízes pelas partes, de entre os mais conhecedores daquela 
matéria; acrescido rigor e profundidade das decisões; mais cuidadosa "personalização" da decisão, em termos de mais aprofundada ponderação da matéria de facto e de Direito, sem atender às jurisprudências deformantes do caso concreto; maior previsibilidade da justiça da decisão - daí renúncia a pretensões inviáveis; etc.

Nota-se que as vantagens da arbitragem tributária repousam em aspectos ligados à própria certeza e segurança do Direito, dois aspectos fundamentais para que se possa construir um sistema tributário nacional mais racional e justo.

Importante destacar que tramita no Congresso Nacional o Projeto de Lei 4.257, de 6 de agosto de 2019 (BRASIL, 2019), do senador Antonio Anastasia (PSDB - MG), propondo a modificação da Lei de Execuções Fiscais (Lei 6.830, de 22 de setembro de 1980) e instituindo duas figuras jurídicas de extrema relevância: a execução fiscal administrativa e a arbitragem tributária.

Conforme sustentam Saulo Gonçalves Santos e Rômulo Guilherme Leitão (2019, p. 471), "com a ampliação dos mecanismos alternativos de resolução de disputas, se concretiza um sistema multiportas de administração de controvérsias", sendo imperioso a participação da Administração Pública em procedimentos arbitrais.

Assim, defende Camila Siqueira Xavier, que "a arbitragem firmada por meio do compromisso arbitral representa um método adequado para resolução de lidas tributárias (complementar ao contencioso judicial e ao contencioso administrativo)", considerando-se assim uma "terceira via de impugnação do crédito tributário já constituído, além de trazer eficácia na prevenção de litígios, através da cláusula compromissória previamente firmada" (2019, p. 32).

A bem da verdade, a arbitragem tributária tem a importante função de se apresentar como uma via adequada e complementar para resolução de determinados conflitos de natureza fiscal, operando uma espécie de desjudicialização de demandas, motivo pelo qual o projeto deve ser debatido no Congresso Nacional com a urgência que o tema demanda, vez que possível contribuições para resolver a crise fiscal do Estado é tema de primeira ordem na pauta de desenvolvimento nacional.

\section{O PAPEL DO ADVOGADO NAS DEMANDAS ARBITRAIS}

Como já mencionado, a advocacia passa por um momento histórico de profundas transformações, impulsionado pelo esgotamento do Poder Judiciário e pela necessidade de que seja assumido um papel de protagonismo num sistema de prevenção ao litígio, ou mesmo encontrar solução adequada para que os litígios sejam efetivamente resolvidos.

Dentre os mecanismos adequados de solução dos litígios a arbitragem se coloca como importante instrumento, surgindo assim dúvidas em relação as formas pelas quais os advogados podem se colocar como profissionais cuja participação se mostra essencial para que se tenha um resultado eficaz. 
Inicialmente, cumpre mencionar que a própria Lei da Arbitragem (Lei n. 9.307/96) (BRASIL, 1996) torna facultativa a postulação perante um juízo arbitral através de advogado, tal como dispõe:

Art. 21. A arbitragem obedecerá ao procedimento estabelecido pelas partes na convenção de arbitragem, que poderá reportar-se às regras de um órgão arbitral institucional ou entidade especializada, facultando-se, ainda, às partes delegar ao próprio árbitro, ou ao tribunal arbitral, regular o procedimento.

$\S 1^{\circ}$ Não havendo estipulação acerca do procedimento, caberá ao árbitro ou ao tribunal arbitral discipliná-lo.

$\S 2^{\circ}$ Serão, sempre, respeitados no procedimento arbitral os princípios do contraditório, da igualdade das partes, da imparcialidade do árbitro e de seu livre convencimento.

$\S 3^{\circ}$ As partes poderão postular por intermédio de advogado, respeitada, sempre, a faculdade de designar quem as represente ou assista no procedimento arbitral.

$\S 4^{\circ}$ Competirá ao árbitro ou ao tribunal arbitral, no início do procedimento, tentar a conciliação das partes, aplicando-se, no que couber, o art. 28 desta Lei.

Em que pese essa faculdade ser claramente observada, não há que se pensar em exclusão do profissional advogado do processo de constituição e desenvolvimento da solução arbitral.

É preciso lembrar que a arbitragem é solução heterocompositiva de conflitos, porém de nítida base consensual, na que a escolha se dá através de Convenção de Arbitragem, seja ela judicial ou extrajudicialmente. Em ambas as situações, a participação do advogado é fundamental, até pelo fato de que ninguém irá se aventurar juridicamente sem o aconselhamento e acompanhamento de um profissional capacitado.

A ausência de advogados na solução arbitral pode, inclusive, retirar transformar a celeridade e eficiência da solução extrajudicial em problema que futuramente poderá cair novamente na clássica atividade jurisdicional estatal, ou seja, é um preço pelo qual as partes certamente não estão dispostas a pagar.

Há que se perceber que no processo arbitral o advogado aparece como figura verdadeiramente indispensável, porém um profissional que possui novos parâmetros de atuação profissional, dispensando-se a agressividade muitas vezes exigida nos processos tradicionais e entendendo que há renúncia tácita aos instrumentos de procrastinação que são levados a cabo quando da atuação perante o Poder Judiciário. Na arbitragem o que ambas as partes querem é que o conflito seja solucionado da maneira mais eficiente e célere possível, estando os advogados imbuídos desse objetivo.

O primeiro receio na advocacia decorrente da difusão da arbitragem como meio adequado de solução de litígios foi o da exclusão dos profissionais inscritos nos quadros da Ordem dos Advogados do Brasil, isso diante da pretensa faculdade indicada pela Lei da Arbitragem.

Na verdade, o que se vê neste momento é a abertura de novas possibilidades de atuação profissional, dentro da perspectiva de gradativo abandono seletivo das velhas práticas na advocacia. 0 profissional se coloca em um momento decisivo em que precisa se adequar a 
uma realidade bastante clara: o litígio tradicionalmente colocado na órbita do Poder Judiciário vai deixando de ser interessante a todos os atores envolvidos.

Além disso, há que se ter em mente que a própria arbitragem passa por um processo de expansão no Brasil. Como defendido acima, é fundamental que a mesma seja incorporada, por exemplo, ao sistema de resolução de conflitos de natureza fiscal. Assim, na órbita da advocacia tributária, surgirá um novo espaço de atuação para aqueles que se mostrarem abertos a essa nova realidade, que virá, sem dúvida alguma.

A arbitragem tributária no Brasil parece estar na iminência de regulamentação legislativa e para tanto necessitará de uma mudança de postura a concepção por parte dos profissionais da advocacia que militam nessa área bastante específica. Nessa perspectiva, o advogado deve se colocar como um grande facilitador, dando a segurança necessária para que as partes do conflito possam buscar as soluções extrajudiciais, consensuais ou não.

A própria advocacia pública vem passando, em pouquíssimo tempo, por uma profunda modificação na forma de atuação, isso com a incorporação dos mecanismos de solução consensual dos litígios, bem como as formas extrajudiciais já implementadas no âmbito da administração pública.

Assim, não restam dúvidas quanto à importância e indispensabilidade da participação do advogado na construção da arbitragem como mecanismo adequado de solução de conflitos, em que se busca a solução célere e eficaz de litígios.

\section{CONCLUSÃO}

De tudo que foi estudado ao longo do presente trabalho, é possível concluir que o mundo globalizado, a sociedade informacional e o avanço da tecnologia assentam um ambiente que clama pela reinvenção de algumas profissões, sendo a advocacia parte integrante desse contexto.

Em pleno século XXI, os desafios impostos à advocacia, em especial no âmbito tributário, são muitos, especialmente diante do quadro de completo esgotamento da capacidade do Poder Judiciário em resolver, de forma eficiente, os conflitos levados à clássica ideia de jurisdição estatal.

Nesse contexto, é preciso que o profissional da advocacia perceba a necessidade de abandono gradativo ao ideal exclusivo de litigiosidade, avançando sobre um debate relativo à advocacia consultiva e preventiva, às questões de solução consensual dos conflitos, ou mesmo mecanismos extrajudiciais, tal como a arbitragem.

Conclui-se pela plena possibilidade de regulamentação legislativa da arbitragem tributária no Brasil, rompendo-se paradigmas clássicos acerca da supremacia do interesse público e indisponibilidade do crédito tributário.

Surge assim mais uma perspectiva de atuação para o advogado que milita nessa seara, devendo ser ressaltada a importância da participação desse profissional no procedimento arbitral, não havendo assim o risco de desvalorização da advocacia. 
Por fim, conclui-se que talvez o grande desafio da advocacia no século XXI seja incorporar a importância e indispensabilidade da participação do profissional capacitado na construção da arbitragem como mecanismo adequado de solução de conflitos, na busca a solução célere e eficaz de litígios, especialmente os de natureza fiscal.

\section{REFERENNCIAS}

BERALDO, Leonardo de Faria. Curso de arbitragem nos termos da Lei n. 9.307/96. São Paulo: Editora Atlas, 2014. BRANDÃO, Fernanda Holanda de Vasconcelos. Advocacia negocial: promoção do acesso à justiça pela desjudicialização dos conflitos. João Pessoa: A União, 2014.

BRASIL. Conselho Nacional de Justiça. Relatório Justiça em Números 2017: ano-base 2016. Disponível em: http://www.cnj.jus.br/files/conteudo/arquivo/2017/12/ b60a659e5d5cb79337945c1dd137496c.pdf. Acesso em: 20 mar. 2020.

BRASIL, Lei Federal n. 9.307, de 23 de setembro de 1996. Dispõe sobre a arbitragem. Brasília: Congresso Nacional [1996]. Disponível em: http://www.planalto.gov.br/ccivil_03/leis/L9307.htm. Acesso em: 13 mar. 2020.

BRASIL, Lei Federal n. 5.172, de 25 de outubro de 1966. Dispõe sobre o Sistema Tributário Nacional e institui normas gerais de direito tributário aplicáveis à União, Estados e Municípios. Brasília: Congresso Nacional [2007]. Disponível em: http://www.planalto.gov.br/ccivil_03/leis//5172.htm. Acesso em: 21 mar. 2020.

BRASIL. Projeto de Lei 4.257, de 6 de agosto de 2019. Modifica a Lei nº 6.830, de 22 de setembro de 1980, para instituir a execução fiscal administrativa e a arbitragem tributária, nas hipóteses que especifica. Brasília: Senado Federal [2019]. Disponível em: https://www25.senado.leg.br/web/atividade/materias/-/materia/137914. Acesso em: 21 mar. 2020.

CAHALI, Francisco José. Curso de Arbitragem. 5. ed. São Paulo: Editora Revista dos Tribunais, 2015.

CAMPOS. Diogo Leite de. Certeza e segurança no Direito Tributário: a arbitragem. Disponível em: https://portal. oa.pt/comunicacao/publicacoes/revista/ano-2005/ano-65-vol-ii-set-2005/artigos-doutrinais/diogo-leite-de-campos-certeza-e-seguranca-no-direito-tributario-a-arbitragem/. Acesso em: 20 jul. 2019.

CARMONA, Carlos Alberto. A arbitragem no processo civil brasileiro. São Paulo: Malheiros, 1993.

CARNEIRO, Paulo Cezar Pinheiro. Acesso à justiça: juizados especiais cíveis e ação civil pública. Rio de Janeiro: Forense, 1999.

CASELLA, Paulo Borba; ESCOBAR, Marcelo. Arbitragem Tributária e a Câmara de Conciliação e Arbitragem da Administração Federal. In: SCHOUERI, Luis Eduardo; BIANCO, João Francisco (Coords.). CASTRO, Leonardo Freitas de Moraes e; DUARTE FILHO, Paulo César Teixeira (Orgs.). Estudos de Direito Tributário em Homenagem ao Prof. Gerd Willi Rothmann. São Paulo: Quartier Latin, 2016.

LIMA, Martonio Mont'Alverne Barreto; ACIOLY FILHO, Evaldo Ferreira.

Análise da legitimidade democrática do supremo tribunal federal como o "superego da sociedade". Revista Meritum, Belo Horizonte, v. 14, n. 1, p. 80-97, Jan./Jun. 2019. Disponível em: http://www.fumec.br/revistas/meritum/ article/view/6296/pdf. Acesso em: 02 jun. 2020.

LÔBO, Paulo. Comentários ao Estatuto da Advocacia e da OAB. 5ª ed. São Paulo: Saraiva, 2009.

MACEI, Demetrius Nichele; VOSGERAU, Bruno Roberto; ANDRETTA, Juliane Tedesco. O papel do estado pela atuação do poder judiciário nos conflitos contratuais em tempos de pandemia do covid-19: a fraternidade como elemento de decidir. Revista Relações Internacionais do Mundo Atual, v.2, n. 27 2020, abr/jun 2020, 1-24. Disponível em: http://revista.unicuritiba.edu.br/index.php/RIMA/issue/view/158/showToc. Acesso em: 15 maio 2020. 
MACHADO, Hugo de Brito. Transação e arbitragem no direito tributário. In: SARAIVA FILHO, Oswaldo Othon de; GUIMARÃES, Vasco Branco (Orgs.). Transação e arbitragem no âmbito tributário: homenagem ao jurista Carlos Mario da Silva Velloso. São Paulo: Fórum, 2008.

MENDONÇA, Priscila Faricelli de. Arbitragem e transação tributárias. Brasília: Gazeta Jurídica, 2014.

OLIVEIRA, Bruno Bastos de; OLIVEIRA, Maria das Graças Macena Dias de; CARMO, Valter Moura do. A eficiência do sistema multiportas de justiça e a aplicação nos conflitos envolvendo a fazenda pública. Revista Faculdade Direito UFG, v. 43, p.01-15, 2019. Disponível em: https://www.revistas.ufg.br/revfd/article/view/60014. Acesso em: 22 maio 2020.

PINHO, Humberto Dalla Bernardina de; PAUMGARTTEN, Michele Pedrosa. Código de processo civil: quais as perspectivas para a justiça brasileira? In: ALMEIDA, Diogo Assumpção Rezende de. et. al. (Coords.) A mediação no novo código de processo civil. 2. ed. Rio de Janeiro: Forense, 2016.

SANTOS, Saulo Gonçalves; LEITÃO, Rômulo Guilherme. O debate da privatização da jurisdição e a arbitragem tributária no brasil: uma evolução necessária. Revista Meritum, v. 14, n. 2, p. 447-475, Belo Horizonte, Jul./Dez. 2019. Disponível em: http://www.fumec.br/revistas/meritum/article/view/6927. Acesso em: 20 mar. 2020.

SEIXAS FILHO, Aurélio Pitanga. Arbitragem em Direito Tributário. Revista da EMERJ, Rio de Janeiro, v. 11, n. 43, p. 218-232, 2008. Disponível em: http://www.emerj.tjrj.jus.br/revistaemerj_online/edicoes/revista43/ Revista43_218.pdf. Acesso em: 20 mar. 2019.

SILVA, Paulo Eduardo Alves da. Solução de controvérsias: métodos adequados para resultados possíveis e métodos possíveis para resultados adequados. In: SALLES, Carlos Alberto. et. al. (Coords.). Negociação, mediação e arbitragem: curso para programas de graduação em Direito. São Paulo: Método, 2012.

SILVA, Sabrina Jiukoski da; SANTOS, Ricardo Soares Stersi dos; SILVA, Rafael Peteffi da. A mediação e a conciliação como instrumentos de acesso à

Justiça e a sua perspectiva a partir do código de processo civil: o contraponto entre a cultura da sentença e a cultura do consenso. Revista Eletrônica de Direito Processual - REDP. Rio de Janeiro, ano 14, v. 21, n. 1, jan/abr 2020. Disponível em: https://www.e-publicacoes.uerj.br/index.php/redp/article/view/44635. Acesso em: 20 maio 2020.

VECCHIO, Fausto. O Estado Constitucional em Perigo: crise da representação e instituições judiciais sob ataque. Revista de Direito Público RDP, Brasília, Volume 17, n. 91, 9-27, jan./fev. 2020. Disponível em: https://www.portaldeperiodicos.idp.edu.br/direitopublico/article/view/4026. Acesso em: 15 maio 2020.

VITA, Jonathan Barros. Arbitragem e Poder Público: uma nova abordagem. In: Aspectos práticos da arbitragem. Luiz Fernando do Vale de Almeida Guilherme (Coord.). São Paulo: Quartier Latin, 2006.

XAVIER, Camila Siqueira. A arbitragem em matéria tributária no brasil: avanços e desafios. Revista de Finanças Públicas, Tributação e Desenvolvimento, v. 7, n. 8, janeiro/junho, 2019, p. 21-57. Disponível em: https://www.e-publicacoes.uerj.br/index.php/rfptd/article/view/36609. Acesso em: 20 maio 2020.

Recebido/Received: 23.04.2020.

Aprovado/Approved: 04.06.2020. 